\title{
Formation of deprotonated 2-imidazoline-4(5)-one product ions in the collision- induced dissociation of some serine-containing dipeptides
}

\author{
James S. Swan ${ }^{\mathrm{a} *}$, Peter M. Findeis ${ }^{\mathrm{a}}$, Sheena Hilton ${ }^{\mathrm{a}, \mathrm{b}}$, Kathryn M. Lebold ${ }^{\mathrm{a}}$, Berhane \\ Temelso ${ }^{\mathrm{a}}$, George C. Shields ${ }^{\mathrm{a}, \mathrm{c}}$ \\ ${ }^{a}$ Department of Chemistry, Bucknell University, Lewisburg, PA, United States \\ ${ }^{\mathrm{b}}$ Phillips Academy, Andover, MA, United States \\ c Dean's Office, College of Arts and Sciences, Bucknell University, Lewisburg, PA, United States
}

\begin{abstract}
A deprotonated 2-imidazoline-4(5)-one product ion was observed as a major fragment in the Collision-Induced Dissociation (CID) of several dipeptides containing serine at the Cterminal and an amino acid with an alkyl substituent at the $\mathrm{N}$-terminal. This fragment becomes predominant at high collision energies. The same type of product ion was seen in the CID of cyclo(GlyGly). Labeling GlySer with O-18 suggests that the fragmentation may proceed through a symmetrical intermediate such as a deprotonated diketopiperazine. Density functional theory calculations of GlySer provided a possible mechanism for the fragmentation.
\end{abstract}

Keywords: Deprotonated dipeptide, Peptide fragmentation, 2-Imidazoline-4(5)-one, Density functional theory, Diketopiperazine

\section{Introduction}

Although positive ion mass spectrometry has dominated the techniques used to analyze protein and peptide structure [1-4], it has also been recognized that negative ion mass spectrometry can contribute complementary (and sometimes unique) information on protein and peptide identity and sequence [5-8]. Despite the increasing attention being paid to negative ions [9 10], it has been recently noted that more work is still needed to fully understand the Collision Induced Dissociation (CID) of deprotonated peptides [11]. The work presented here adds to the knowledge base of negative ion fragmentations. The discussion of negative ions will use the Roepstorff-type nomenclature [5, 12], where the $\mathrm{y}_{1}$ fragment is the deprotonated $\mathrm{C}$-terminal amino acid resulting from cleavage of the peptide bond.

Peptide negative ions most commonly arise from a deprotonated carboxylic acid group, either as a side chain or as the C-terminus. Negative enolate ions can also form, either directly or by proton transfer to a carboxylate ion $[6,13]$. When serine is present in a peptide during CID an enolate ion can form at the alpha carbon through the loss of the serine side chain as formaldehyde $\left(\mathrm{CH}_{2} \mathrm{O}\right)$, in many cases forming the base peak of the spectrum [14]. Subsequent fragmentations of serine containing peptides can occur through the parent $[\mathrm{M}-\mathrm{H}]^{-}$species as well as from the $\left[\mathrm{M}-\mathrm{H}-\left(\mathrm{CH}_{2} \mathrm{O}\right)\right]^{-}$species $[7,15]$. White and co-workers showed that at low collision energy GlySer can lose formaldehyde through a McLafferty-type rearrangement [16].

The mechanisms of peptide fragmentations and structures of the resulting peptide ions have been extensively studied, often utilizing infrared multiple photon dissociation 
(IRMPD) spectroscopy and density functional theory (DFT) calculations [17]. Recent reports indicate the importance of rearrangements in the fragmentation of ions, especially in triple quadrupole collision cells under multiple collision conditions [18]. It has also been pointed out that unusual ions from secondary fragmentations may be able to improve the reliability of peptide identifications [19].

Two commonly proposed structure types in positive ion fragmentations are diketopiperazine (DKP) and oxazolone rings, with the pathway of formation and final structure being somewhat dependent on the amino acid residues involved [20, 21, 22], and on experimental parameters such as collision energy [17].

Negative ion fragmentations have been less well studied than those from positive ions, but early computational studies by Harrison and co-workers [23] indicated that fragmentation pathways are conformationally sensitive, and with the energy available in mass spectrometer systems, many different rotamers of a deprotonated peptide could be significant in deprotonation and fragmentation reactions. Grzetic and Oomens have published several recent reports on structures of small deprotonated peptide fragments [24-26]. Based on IRMPD spectra, they showed that anionic $b_{2}$ fragments from AlaAlaAla and AlaTyrAla have an oxazolone structure even though computational results indicated that DKP structures would be thermodynamically favored. The formation of the less favored oxazolone structure was suggested to be due to the fact that formation of the DKP structure would require a trans to cis isomerization of the peptide bond, resulting in a higher energy transition state for DKP formation [24]. In a study of anionic c-type fragments from some short peptides, IRMPD spectroscopy indicated that all the c-type fragments studied had linear structures [25]. Infrared spectroscopy was also used to show that the $b_{2}$ and $b_{3}$ fragment anions from peptides containing Asn do not contain oxazolone or DKP structures, but rather involve cyclization of the asparagine side chain [26].

Only a few other studies of deprotonated peptides mention DKPs. Harrison and Young considered DKPs as being possibly involved in an ion-neutral complex from which neutral benzene is eliminated in the fragmentation of deprotonated N-Benzoylpeptides, but they were unable to clearly elucidate the pathway [27]. Bradford et al. suggested possible deprotonated DKP formation from digycine methyl ester in high-energy fast atom bombardment CID [28]. This report also suggested a possible pathway involving proton transfer to an enolate position that would result in a negatively charged Nterminus that could then cyclize to form a deprotonated DKP. Another mention of DKPs came in a report by Cassady and co-workers on the effects of amide and acid groups at the C-terminus of deprotonated peptides [10]. They showed that substituted DKPs served as neutral leaving groups in the CID formation of c-type fragments from deprotonated peptide amides.

There have also been studies of the fragmentation of protonated [29] and deprotonated [30, 31] cyclic dipeptides, which exist as 2,5 DKPs. Bowie and co-workers [29] used negative chemical ionization to examine the mass spectra of various 2,5-DKPs, including cyclo-(GlyGly). They used an ionizing energy of $70 \mathrm{eV}$, an accelerating voltage of $7 \mathrm{kV}$, and $\mathrm{HO}^{-}$(from $\mathrm{H}_{2} \mathrm{O}$ ) to deprotonate the DKPs. In their study of cyclo-(GlyGly) they reported that the major product ion results from the loss of the elements of $\mathrm{CH}_{2} \mathrm{O}$ to yield a deprotonated 2-imidazoline-4(5)-one. Using ${ }^{13} \mathrm{C}$ labeling the study also demonstrated that oxygen migration was not involved in the loss of $\mathrm{CH}_{2} \mathrm{O}$, meaning that two hydrogens 
must have been transferred to the carbonyl group of the $\mathrm{CH}_{2} \mathrm{O}$. In a more recent study, Cao, Zhao, and co-workers [31] reported on the fragmentation of deprotonated cyclic dipeptides by Electrospray Ionization (ESI)-MS/MS using an ion trap mass spectrometer interfaced with an ESI source. Although they did not look specifically at cyclo-(GlyGly), for other cyclic dipeptides containing only alkyl groups they reported a major product ion that is a deprotonated 2-imidazoline-4(5)-one, which they suggest is formed by the consecutive elimination of a molecule of $\mathrm{CO}$ and a saturated substituent $(\mathrm{R}+\mathrm{H}$, which would be $\mathrm{H}_{2}$ in the case of cyclo-(GlyGly)).

In this paper we report on our studies of the ESI-CID of a series of deprotonated dipeptides containing serine at the $\mathrm{C}$-terminus and an amino acid with an alkyl substituent as the N-terminus. Mechanistic and computational studies focus on GlySer. At moderately high CID collision energies we have found a major product ion (in some cases the base peak) that we propose to be a deprotonated 2-imidazoline-4(5)-one. The mechanism we suggest starts with the formation of an enolate ion by the loss of the serine side chain as $\mathrm{CH}_{2} \mathrm{O}$, and proceeds through a deprotonated DKP intermediate which can lose another $\mathrm{CH}_{2} \mathrm{O}$ molecule from either carbonyl of the DKP (as evidenced by ${ }^{18} \mathrm{O}$ labeling). Our suggested mechanism was derived using literature precedent and DFT calculations.

\section{Experimental and computational methods}

\subsection{Dipeptide samples}

The dipeptides were obtained from Sigma-Aldrich (St. Louis, MO) and Bachem Americas (Torrance, CA). The dipeptides were used as received and dissolved in $3 \mathrm{mM}$ ammonium formate (Fluka, 99.0\%) in 1:1 methanol/water. GlySer used for ${ }^{18} \mathrm{O}$ labeling was dissolved in 5\% formic acid. Dipeptide solutions were prepared at concentrations ranging from $0.15 \mathrm{mM}$ to $6.7 \mathrm{mM}$.

\section{2. ${ }^{18}$ O labeling}

The ${ }^{18} \mathrm{O}$ labeling reaction was inspired by published reports demonstrating that the oxygen atoms of carboxyl groups can be exchanged with those of solvent water under acidic conditions [32-34]. Oxygen exchange increases with reaction time and temperature, but so does peptide hydrolysis.

A $6.7 \mathrm{mM}$ solution of GlySer was prepared in 5\% formic acid (Fisher Optima). The reaction was performed by mixing 50 microliters of the GlySer solution with an equal volume of $\mathrm{H}_{2}{ }^{18} \mathrm{O}$ (Aldrich, 97 atom $\%{ }^{18} \mathrm{O}$ ) in a $1.0 \mathrm{~mL}$ screw-top reaction vial. The reaction vial was sealed and placed in a solid block heater for 8 hours at $110{ }^{\circ} \mathrm{C}$. Aliquots (1-3 microliters) of the reaction mixture were injected into the PE/Sciex API III+ mass spectrometer using a mobile phase of $3 \mathrm{mM}$ ammonium formate in 1:1 methanol:water.

\subsection{Mass Spectrometry}

The data for the dipeptides in Table 1 were obtained with a Micromass Q-Tof micro instrument, the exact mass measurement of Species 9 from GlySer was determined using 
a Thermo Scientific Exactive ${ }^{\mathrm{TM}}$ Orbitrap mass spectrometer, and all other mass spectrometry and CID data were obtained with a Perkin-Elmer/Sciex API III+ triple quadrupole mass spectrometer. The collision energies reported for the PE/Sciex instrument are the difference in potential between the first and second quadrupoles. Dipeptides were introduced into the mass spectrometer either by direct infusion at a flow of 5-30 microliters per minute, or by flow injection using the given solvent and flow, with injections of 1-3 microliters of dipeptide solution. Ion Spray voltages ranged from 2100 to $-3000 \mathrm{~V}$. Collision gas thickness was normally $200 \times 10^{13}$ molecules $/ \mathrm{cm}^{2}$ (multiple-collision conditions), and the collision gas for the Sciex instrument was a mixture of $90 \% \mathrm{Ar}$ and $10 \% \mathrm{~N}_{2}$.

Results were comparable between the Q-Tof and Sciex instruments, but there were slight differences in effective collision energies and collision gas thicknesses. The Q-Tof does not scan below $\mathrm{m} / \mathrm{z} 50$, which slightly affects the \%Total Ion Current (\%TIC) values calculated.

\subsection{Density functional theory calculations}

Initial conformers were created by generating 60 rotamers of GlySer and minimizing using the Merck molecular force field MMFF94 [35]. The unique conformers were then minimized using DFT with the M06-2X functional [36] and 6-311++G** basis set, and the two lowest energy cis conformers were considered for all subsequent calculations. The cis conformers were $3.5-4.7 \mathrm{kcal} / \mathrm{mol}$ higher in energy than the global minimum for deprotonated GlySer, with a $20 \mathrm{kcal} / \mathrm{mol}$ barrier to the trans-cis isomerization. The structures of the low energy isomers and the trans-cis isomerization potential are shown in Fig. S2 and S3 of the supplementary materials. Each intermediate and transition state was determined using Gaussian 09 [37]. The validity of each transition state and the reaction pathway was then verified by Intrinsic Reaction Coordinate (IRC) calculations connecting the transition state both to the reactant and product. The functional and basis set M06-2X/6-311++G** were used for all calculations.

\section{Results and Discussion}

\subsection{GlySer fragmentation}

Early studies on deprotonated dipeptides containing serine were carried out by Bowie and co-workers in 1990 [14]. They performed collisional activation FAB (Fast Atom Bombardment) mass spectrometry with a VG ZAB $2 \mathrm{HF}$ mass spectrometer, and consecutive collision induced dissociations using a Kratos MS 50 TA instrument with an accelerating voltage of $8 \mathrm{kV}$. These studies showed that the predominant fragmentation was the loss of the serine side chain as formaldehyde, irrespective of the position of serine in the dipeptide. When serine was on the N-terminus, a normal $\mathrm{y}_{1}$ fragment of the deprotonated $\mathrm{C}$-terminal amino acid was seen. When serine was on the C-terminus, either no $\mathrm{y}_{1}$ fragment was detected or only a small $\mathrm{y}_{1}$ peak was seen. In this situation a fragment corresponding to a $\mathrm{y}_{1}$-type fragment of $\left([\mathrm{M}-\mathrm{H}]-\mathrm{CH}_{2} \mathrm{O}\right)$ was seen. The diagnostic fragmentation for identifying serine as the $\mathrm{C}$-terminal amino acid was reported to be the loss of $\left(\mathrm{CO}_{2}+\mathrm{H}_{2} \mathrm{O}\right)$. 
Fig. 1 shows the important sequential fragments (Species 1, 3, 5, and 9) obtained from GlySer. Two other fragments are useful for demonstrating the location of inserted ${ }^{18} \mathrm{O}$; the loss of $\left(\mathrm{CO}_{2}+\mathrm{H}_{2} \mathrm{O}\right)$ gives $\mathrm{m} / \mathrm{z} 99$, and the $\mathrm{y}_{1}$-type fragment that has lost the serine side chain has an $\mathrm{m} / \mathrm{z}$ of 74 . The fragment at $\mathrm{m} / \mathrm{z} 42$ provides more evidence of a concordance between GlySer and cyclo(GlyGly) as discussed later. Species 9, which was not reported in earlier work [14] becomes the most prominent fragment at moderately high collision energies.

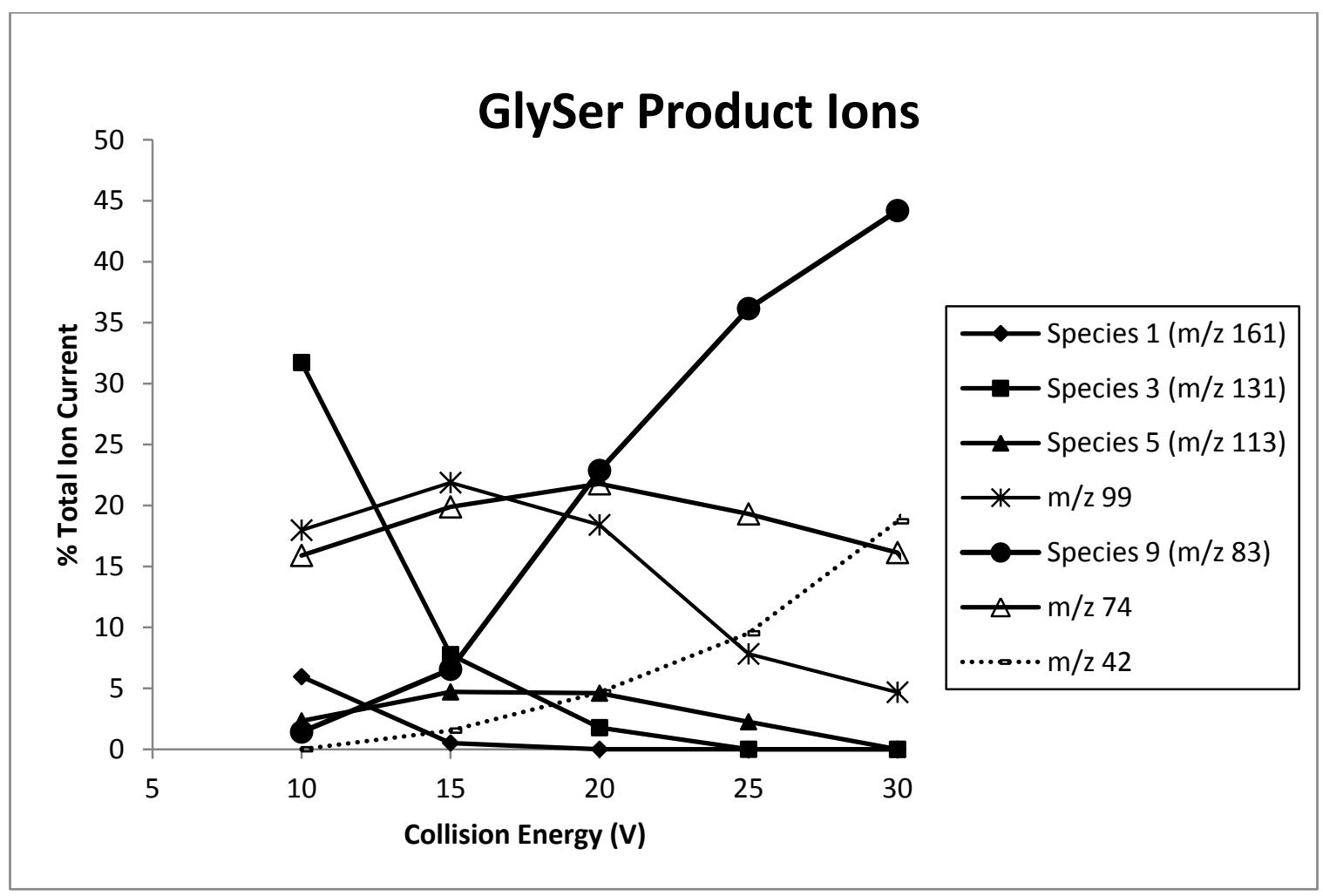

Fig. 1. Product ions of GlySer determined with a Perkin-Elmer/Sciex API III+

A series of product ion scans and a precursor ion scan suggested that Species 9 is formed in a sequence of fragmentations where the initial precursor ion Species $1(\mathrm{~m} / \mathrm{z}$ 161) loses formaldehyde to produce Species 3 (m/z 131), which then loses water to yield Species $5(\mathrm{~m} / \mathrm{z} 113)$, which finally loses another molecule of formaldehyde to yield Species $9(\mathrm{~m} / \mathrm{z} 83)$. Studies of other dipeptides with a C-terminal serine and an $\mathrm{N}$ terminal amino acid with an alkyl side-chain showed the same pattern of fragments, as seen in Table 1. The $\mathrm{m} / \mathrm{z}$ of Species 9 for each dipeptide differs by the mass of the side chain of the respective N-terminal amino acid (GlySer gives Species 9 at m/z 83, AlaSer gives Species 9 at $\mathrm{m} / \mathrm{z}$ 97, ValSer gives Species 9 at $\mathrm{m} / \mathrm{z} 125$, etc. This indicates that Species 9 contains the side chain of the N-terminal amino acid, making it similar to an atype fragment, but unlike an a-type fragment the side chain of the C-terminal Ser was lost in the first fragmentation, and the C-terminal carbonyl is not always lost (as shown by ${ }^{18} \mathrm{O}$ labeling, discussed later). The dipeptide GlySer was focused on for mechanistic and DFT studies. 
Exact mass measurement of Species 9 from GlySer using an orbitrap mass spectrometer indicated that the molecular formula of Species 9 from GlySer was $\mathrm{C}_{3} \mathrm{H}_{3} \mathrm{~N}_{2} \mathrm{O}$. This molecular formula correlates with the structure of deprotonated 2-imidazoline-4(5)-one (shown in Scheme 1), which is the product ion reported by Bowie and co-workers [30] in the negative chemical ionization of cyclo-(GlyGly), and verified by ESI-MS-MS as shown in Figure S1. Zhao and co-workers [31] reported analogous product ions from cyclic dipeptides containing alkyl side chains.

Table 1. Sequential fragment percent total ion current (\% TIC) from serine-containing dipeptides at given collision energies. Species 1, 3, 5, and 9 are represented in Scheme 1 for GlySer.

\begin{tabular}{|c|c|c|c|c|c|c|}
\hline & & GlySer & AlaSer & ValSer & LeuSer & IleSer \\
\hline \multirow{4}{*}{$\begin{array}{c}\text { Species } 1 \\
{[\mathrm{M}-\mathrm{H}]^{-}}\end{array}$} & $\mathbf{m} / \mathbf{z}$ & 161 & 175 & 203 & 217 & 217 \\
\hline & $10 \mathrm{~V}$ & (23) & (36) & (40) & (41) & (43) \\
\hline & $20 \mathrm{~V}$ & $(0)$ & $(0.2)$ & $(0.4)$ & $(0.6)$ & $(0.4)$ \\
\hline & $30 \mathrm{~V}$ & $(0)$ & $(0)$ & $(0.04)$ & $(0.05)$ & $(0)$ \\
\hline \multirow{4}{*}{ Species 3} & $\mathbf{m} / \mathbf{z}$ & 131 & 145 & 173 & 187 & 187 \\
\hline & $10 \mathrm{~V}$ & (41) & (40) & (30) & (25) & (27) \\
\hline & $20 \mathrm{~V}$ & (3.3) & (8.5) & (12) & (12) & (12) \\
\hline & $30 \mathrm{~V}$ & $(0.1)$ & $(0.3)$ & $(0.7)$ & $(0.2)$ & $(0.6)$ \\
\hline \multirow{4}{*}{ Species 5} & $\mathbf{m} / \mathbf{z}$ & 113 & 127 & 155 & 169 & 169 \\
\hline & $10 \mathrm{~V}$ & $(0.7)$ & $(0.6)$ & $(0.6)$ & $(0.7)$ & $(0.8)$ \\
\hline & $20 \mathrm{~V}$ & (6.6) & (5.8) & $(5.6)$ & $(5.0)$ & $(5.8)$ \\
\hline & $30 \mathrm{~V}$ & (1.8) & $(2.1)$ & $(3.6)$ & $(1.2)$ & (1.6) \\
\hline \multirow{4}{*}{ Species 9} & $\mathbf{m} / \mathbf{z}$ & 83 & 97 & 125 & 139 & 139 \\
\hline & $10 \mathrm{~V}$ & (0) & $(0.04)$ & $(0.02)$ & $(0)$ & (0) \\
\hline & $20 \mathrm{~V}$ & (9.1) & $(6.0)$ & $(3.3)$ & (1.9) & $(2.8)$ \\
\hline & $30 \mathrm{~V}$ & (35) & (30) & (24) & (11) & (15) \\
\hline
\end{tabular}

The first mechanism proposed for the formation of Species 9 from GlySer began with the well-established loss of formaldehyde and formation of the alpha enolate ion. The enolate was then postulated to loose water through a proton transfer followed by formation of an ion-neutral complex between a neutral ketene and hydroxide (as proposed by Kanawati for oxocarboxylic acids [38,39]), which would then be followed by cyclization. DFT studies were unable to find an energy-well for the ion-neutral complex, suggesting that it was unlikely that water loss would occur in that fashion under the given conditions. Several different conformers of GlySer were examined as candidates for Species 1 in the fragmentation sequence to Species 9. The conformation of the dipeptide used in the calculations was cis, as that was found to provide the most favorable pathway to the formation of Species 9. Kanawati mentions the importance of conformational state (and chain length) on the fragmentation of the oxocarboxylic acids [38,39]. Since Species 9 does not become a major fragment until moderately high collision energies are used, it is reasonable that a higher energy Species 1 (cis) would be involved.

A proposed mechanism for the formation of Species 9 from GlySer is shown in Scheme 1. The mechanism was developed based on the fragments shown in Fig. 1 and Table 1, 


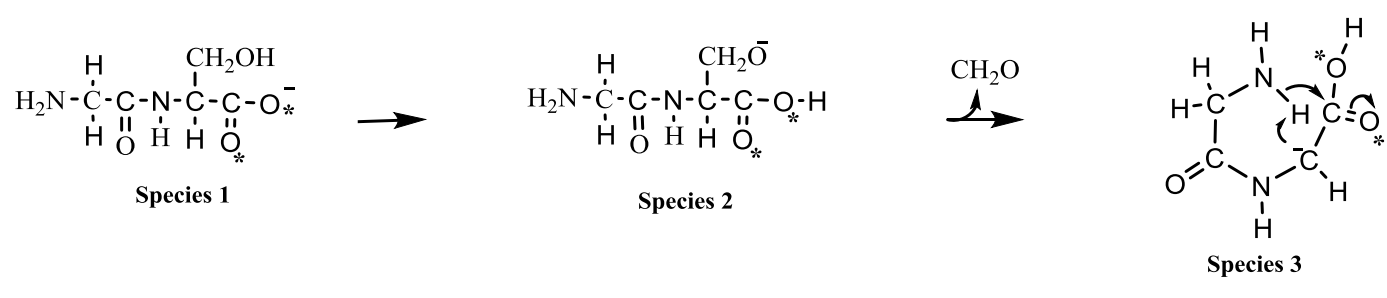

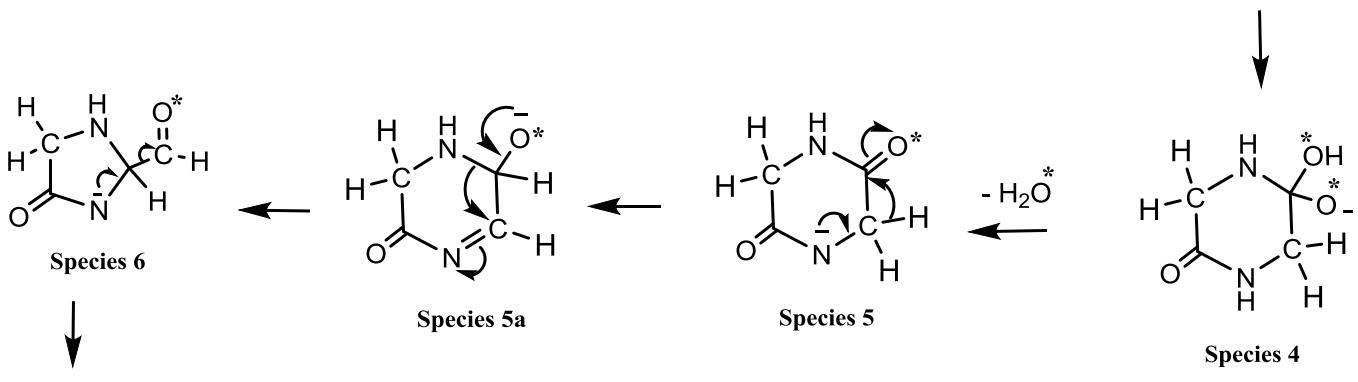

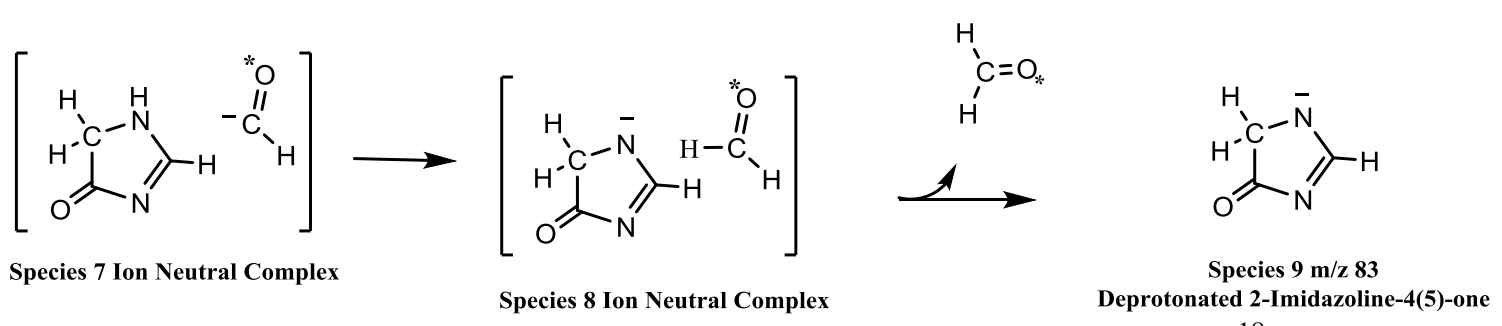

Scheme 1. Possible GlySer fragmentation mechanism. Asterisk(*) marks ${ }^{18} \mathrm{O}$. Due to symmetric transitions, Species 9 could result with $\mathrm{m} / \mathrm{z} 83$ or 85 .

on related fragmentations in the literature, and on DFT calculations. Although only four distinct sequential product ions are seen in Fig. 1 and Table 1, the mechanism proposes several rearrangements of ions, in accord with the observation of the importance of rearrangements reported by White and co-workers [18].

Although the mechanism in Scheme 1 is shown producing Species 9 retaining a potentially labeled oxygen atom, due to symmetrical transitions Species 9 could be produced with or without the labeled oxygen.

The mechanism in Scheme 1 begins with a cis conformation of GlySer that has a hydrogen bond between the carboxylate and an amino hydrogen (Conformer 1 in Fig. S2). The expected loss of the serine side chain as formaldehyde [14] produces the alpha enolate ion as Species 3. Species 3 then proceeds through the transfer of a proton from the N-terminal amino group to the enolate carbon, followed by cyclization of the cis Species 3 to form a 6-member ring, analogous to a suggested cyclization step in the fragmentation mechanism for GlyGly methyl ester [28]. The conversion of Species 3 to Species 4 is shown in Fig. 2. Both the proton transfer and the cyclization happen in the same step, presumably due to the proximity of the reacting sites and the energy available. As previously mentioned, it is reasonable to expect that with the given collision energy and multiple-collision conditions the cis conformer should be available. DFT calculations showed that the Species 1 cis and trans isomers of GlySer are close in energy, although there is a $20 \mathrm{kcal} / \mathrm{mol}$ barrier to the trans-cis isomerization. Chass et al. [23] suggested that the formation of a deprotonated DKP was energetically accessible in the elimination of benzene from N-benzoylglycylglycine, and in the elimination of 

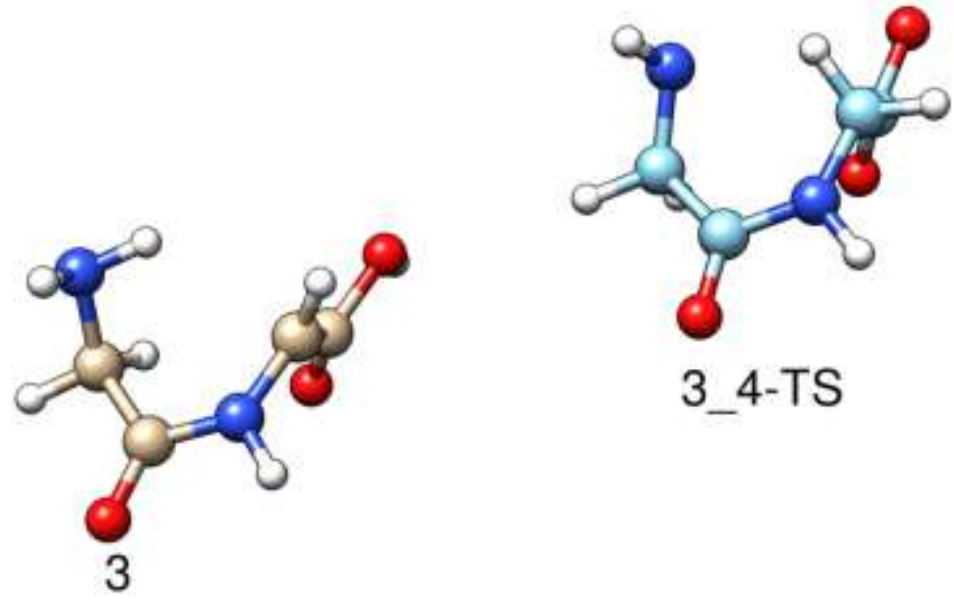

Fig. 2. Species 3 to Species 4 conversion. Relative energies are given in Fig. 3.

dimethylamine from H-Gly-Sar-Sar-OH, so there is precedent for such reactions. The energy profile in Fig. 3 shows the transition state for the proton transfer and cyclization (step 3, TS 3-4) to be $34 \mathrm{kcal} / \mathrm{mol}$ higher in energy than Species 3. Step 4 involves the

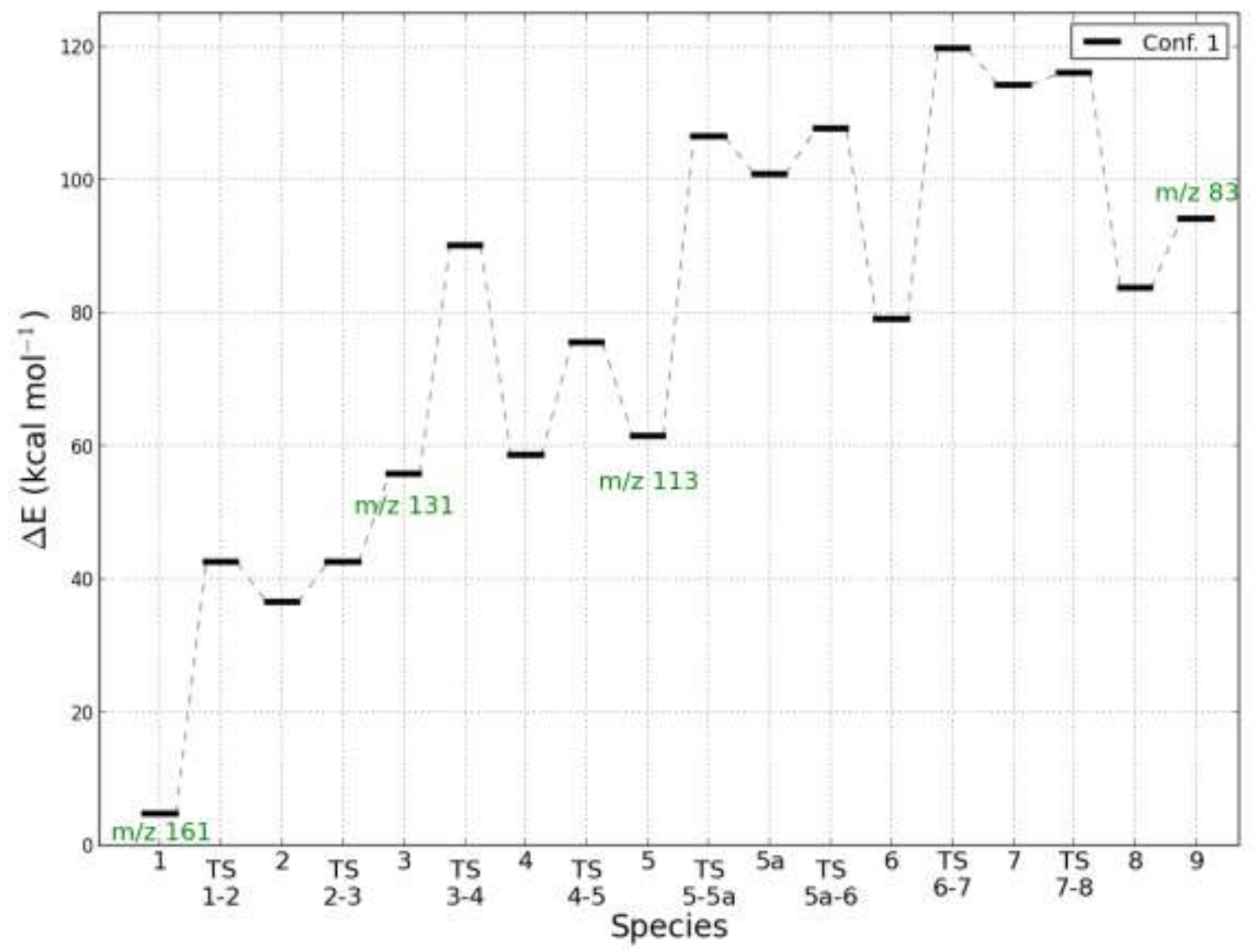

Fig. 3. Energy profile for GlySer fragmentation. Species and transition states are identified on the $\mathrm{x}$-axis. 
loss of hydroxide ion and a proton to yield a molecule of water, as Species 4 reacts to form a deprotonated DKP (Species 5). Bowie and co-workers [30] used chemical ionization with hydroxide ion to form deprotonated DKP from cyclo-(GlyGly), so it is not surprising that the intrinsically produced hydroxide in Scheme 1 would quickly abstract a proton. The proton abstracted to produce water results in a negative charge in the DKP, the position of which ultimately determines which oxygen atom will be lost as formaldehyde in step 8 and which oxygen will be retained in the final deprotonated 2imidazoline-4(5)-one. The proton that is abstracted from Species 4 to produce water can theoretically come from either a lactam nitrogen (as shown) or from a carbon atom. The transition state for the Species 4 to 5 conversion (Fig. 4) shows that the hydroxide could abstract a proton from either lactam group to yield an amide ion. Removal of a proton from one of the DKP carbon atoms to give an enolate ion could be seen when starting with conformer 2 of Species 1 (Fig. S6), but it was less thermodynamically favorable then the lactam deprotonation, and DFT calculations were unable to demonstrate a viable separate mechanism to produce Species 9 from carbon deprotonation of the DKP. In their work on cyclo-(GlyGly) [30] Bowie and co-workers reported that when both nitrogen atoms of the DKP are labeled with deuterium, [M-D] is formed in much greater abundance than $[\mathrm{M}-\mathrm{H}]^{-}$. Other groups have also reported that the preferred site of deprotonation on DKP is the lactam nitrogen, but that carbon deprotonation could also be accessible in CID [23, 27, 31]. The lactam-deprotonated Species 5 is therefore consistent with literature considerations. Calculations showed that if carbon deprotonation did occur, the enolate version of Species 5 could convert to the Species 5 in Scheme 1 by a single proton transfer from the lactam nitrogen to the carbon atom (Fig. S8). This transition would have an energy barrier of $46 \mathrm{kcal} / \mathrm{mol}$.

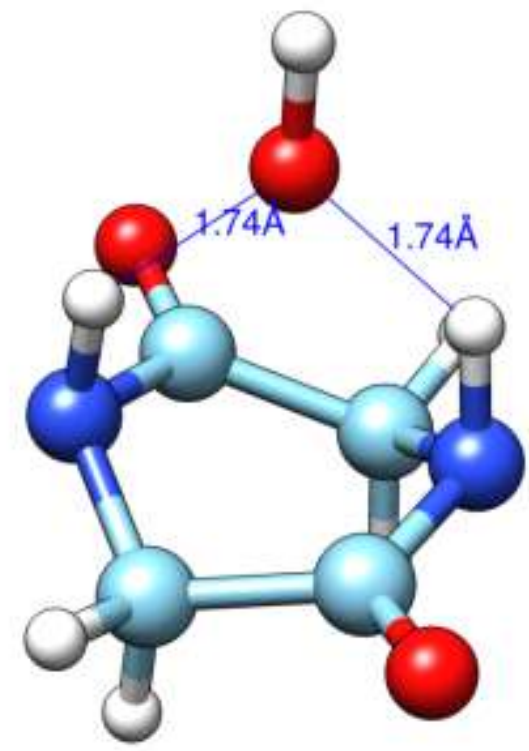

Fig. 4. Species 4 to 5 Transition State.

The loss of a second molecule of formaldehyde (Species 6,7, 8, 9) is proposed to go through an ion neutral complex in a similar manner to that suggested by Bowie for cyclo(GlyGly) [30]. DFT calculations show the presence of two ion neutral complexes (Species 7 and 8) involved in the loss of this second molecule of formaldehyde. Species 7 
has the negative charge on the formyl group, while Species 8 has transferred a proton to place the negative charge on the imidazoline unit. The Species 8 ion neutral complex is bound by $11 \mathrm{kcal} / \mathrm{mol}$ and loses formaldehyde to form Species 9 .

The mechanism in Scheme 1 has aspects that are similar to those reported by Bowie's group for diglycine methyl ester [28] and cyco-(GlyGly) [30], suggesting that the GlySer mechanism could go through a cyclic intermediate like a DKP.

\section{2. ${ }^{18} \mathrm{O}$ exchange experiments}

In order to gain more information on the proposed mechanism, the oxygen atoms of the $\mathrm{C}$-terminal carboxyl group of GlySer were exchanged for ${ }^{18} \mathrm{O}$. This results in one of the oxygens of Species 5 being ${ }^{18} \mathrm{O}$, while the other remains ${ }^{16} \mathrm{O}$, enabling the determination of where each oxygen atom ends up in the final fragmentation product. Since only about $20 \%$ of the GlySer exchanged two oxygen atoms (Fig. 5), the first quadrupole of the Sciex was used to select for $\mathrm{m} / \mathrm{z} 165\left([\mathrm{M}-\mathrm{H}]^{-}\right.$of GlySer with two ${ }^{18} \mathrm{O}$ atoms) from m/z 161 and $\mathrm{m} / \mathrm{z} 163$, and then send it on to the collision cell. To ensure that the two ${ }^{18} \mathrm{O}$ atoms were in the Serine carboxyl, the CID was monitored to verify that $\left[\mathrm{M}-\mathrm{H}-\left(\mathrm{CO}_{2}+\right.\right.$ $\mathrm{H}_{2} \mathrm{O}$ ) $]^{-}$remained at $\mathrm{m} / \mathrm{z} 99$ (still contains the Gly carbonyl) and the $\mathrm{y}_{1}$ type fragment from [M-H - $\left.\left(\mathrm{CH}_{2} \mathrm{O}\right)\right]^{-}$changed from $\mathrm{m} / \mathrm{z} 74$ to $\mathrm{m} / \mathrm{z} 78$ (still contains the Ser carboxylate). If the mechanism proceeds as shown in Scheme $1\left({ }^{18} \mathrm{O}\right.$ atoms indicated with asterisk*), no ${ }^{18} \mathrm{O}$ will be present in Species 9 and the $\mathrm{m} / \mathrm{z}$ should remain at 83 . If an ${ }^{18} \mathrm{O}$ is part of Species 9 , the $\mathrm{m} / \mathrm{z}$ will increase to 85 .

A total of 8 injections from 3 different ${ }^{18} \mathrm{O}$ reaction mixtures were performed at a

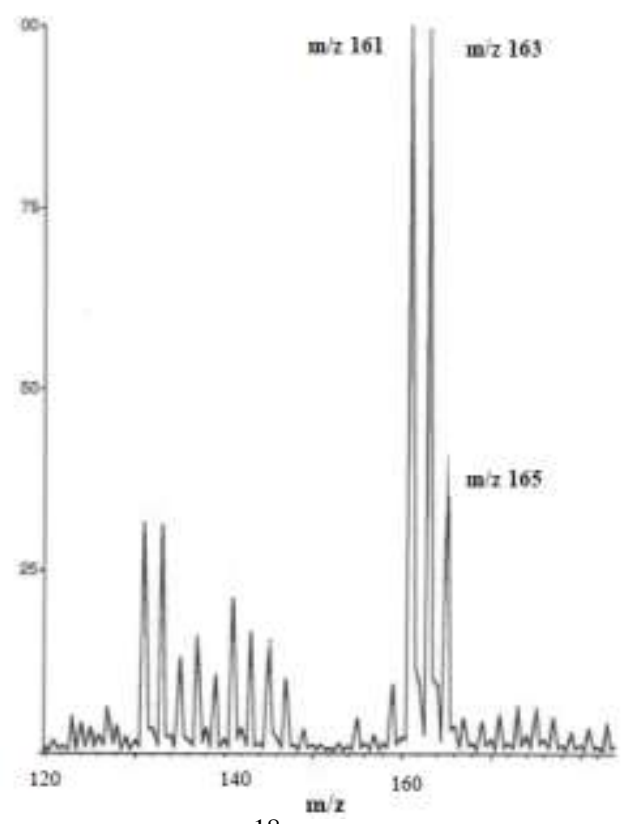

Fig. 5. GlySer ${ }^{18} \mathrm{O}$ exchange. Fragment $\mathrm{m} / \mathrm{z} 165$ contains two ${ }^{18} \mathrm{O}$ atoms.

collision energy of $25 \mathrm{~V}$. The total ion intensities for $\mathrm{m} / \mathrm{z} 83$ and $\mathrm{m} / \mathrm{z} 85$ were summed for each injection. It was found that on average $\mathrm{m} / \mathrm{z} 85$ provided $46 \%(\operatorname{Std} \mathrm{dev}=4)$ of the summed ion intensities at collision energy $25 \mathrm{~V}$. Control reactions with no ${ }^{18} \mathrm{O}$ showed that a minor fragmentation channel (presumably the loss of $\mathrm{CO}$ as reported by 
Guo, et al. for cyclic dipeptides [31]) can produce a fragment at m/z $85\left(\mathrm{C}_{3} \mathrm{H}_{5} \mathrm{~N}_{2} \mathrm{O}\right)$ which is not Species $9\left(\mathrm{C}_{3} \mathrm{H}_{3} \mathrm{~N}_{2}{ }^{18} \mathrm{O}\right)$. At collision energy $25 \mathrm{~V}$ the control reactions showed an average ion intensity of $9 \%(\mathrm{Std} \mathrm{dev}=5)$ for $\mathrm{m} / \mathrm{z} 85$. When ${ }^{18} \mathrm{O}$ is present in Species 5 , the loss of $\mathrm{CO}$ could theoretically produce either $\mathrm{m} / \mathrm{z} 85\left(\mathrm{C}_{3} \mathrm{H}_{5} \mathrm{~N}_{2} \mathrm{O}\right)$ or $\mathrm{m} / \mathrm{z} 87$ $\left(\mathrm{C}_{3} \mathrm{H}_{5} \mathrm{~N}_{2}{ }^{18} \mathrm{O}\right)$. Assuming that half of the $\mathrm{CO}$ loss from Species 5 containing ${ }^{18} \mathrm{O}$ would produce $\mathrm{m} / \mathrm{z} 85$, an estimate for the production of Species 9 with $\mathrm{m} / \mathrm{z} 85$ is $42 \%$.

Although exact mass determination should be able to distinguish between the Species 9 $\mathrm{m} / \mathrm{z} 85\left(\mathrm{C}_{3} \mathrm{H}_{3} \mathrm{~N}_{2}{ }^{18} \mathrm{O}\right)$ and the $\mathrm{m} / \mathrm{z} 85$ from $\mathrm{CO}$ loss $\left(\mathrm{C}_{3} \mathrm{H}_{5} \mathrm{~N}_{2} \mathrm{O}\right)$, our current capabilities do not allow for the precursor ion selection of $\mathrm{m} / \mathrm{z} 165$ from the mixture of $\mathrm{m} / \mathrm{z} 161, \mathrm{~m} / \mathrm{z}$ 163 , and $\mathrm{m} / \mathrm{z} 165$ for exact mass fragmentation in the orbitrap.

A similar set of injections with ${ }^{18} \mathrm{O}$ containing samples and controls at collision energy $20 \mathrm{~V}$ gave $48 \%(\operatorname{Std} \mathrm{dev}=4) \mathrm{m} / \mathrm{z} 85$ with ${ }^{18} \mathrm{O}$ and $14 \%(\operatorname{Std} \mathrm{dev}=2) \mathrm{m} / \mathrm{z} 85$ in the control, yielding a final estimate of $41 \% \mathrm{~m} / \mathrm{z} 85$ Species 9.

The general conclusion is that a significant amount of Species 9 is formed both with and without retention of the ${ }^{18} \mathrm{O}$.

\section{$3.3{ }^{18}$ O labeled GlySer fragmentation mechanism implications}

The mechanism as shown in Scheme 1 for ${ }^{18} \mathrm{O}$ labeled GlySer results in Species 9 with $\mathrm{m} / \mathrm{z} 83$, but experimental results show a significant amount of Species 9 has $\mathrm{m} / \mathrm{z} 85$. A key step in determining whether Species 9 ends up with $\mathrm{m} / \mathrm{z} 83$ or $\mathrm{m} / \mathrm{z} 85$ is the conversion of Species 4 to Species 5. If the leaving hydroxide ion abstracts a different proton, the ${ }^{18} \mathrm{O}$ can end up in Species 9 instead of in the leaving formaldehyde molecule in step 8. A symmetrical transition state (shown in Fig. 4) was found for the Species 4-5 conversion. This transition state shows hydrogen bonds between the leaving hydroxide and both of the lactam protons. If the hydroxide abstracted a proton from the DKP lactam that is opposite to that shown in Scheme 1, the resulting Species 5 would lead to the retention of the ${ }^{18} \mathrm{O}$ in Species 9 , giving it an $\mathrm{m} / \mathrm{z}$ of 85 . Thus, the Scheme 1 mechanism would be able to give Species 9 both with and without the labeled oxygen atom.

\section{Conclusions}

The finding that product ion Species 9 (deprotonated 2-imidazoline-4(5)-one) is sometimes formed containing the oxygen atom from the original C-terminal serine carboxylate, and sometimes containing the oxygen atom from the original GlySer amide bond suggests that a symmetrical intermediate of some type was formed during fragmentation. The moderately high collision energies and multiple collision conditions used in this study likely provide enough energy to overcome the trans to cis barrier (about $20 \mathrm{kcal} / \mathrm{mol}$ ), which allows Species 1 to be in a cis conformation and facilitates the formation of the cyclic Species 4. Results are consistent with the mechanism proposed in Scheme 1, which goes through a cyclic, deprotonated DKP. The symmetrical transition state for the Species 4 - 5 conversion would permit Species 5 (deprotonated DKP) to be formed via deprotonation of either lactam nitrogen, which would then yield a Species 9 containing either DKP oxygen atom. The fact that cyclo-(GlyGly), a known DKP, has been shown to produce the same deprotonated 2-imidazoline-4(5)-one product ion [30] 
also argues for a DKP intermediate in the GlySer fragmentation. Another concordance between GlySer and cyclo-(GlyGly) is that a prominent fragment from GlySer is seen at $\mathrm{m} / \mathrm{z} 42$ (Fig. 1). A fragment at $\mathrm{m} / \mathrm{z} 42$ is also reported for cyclo-(GlyGly) and is assigned as coming from the retro cleavage of the DKP ring [30]. The $\mathrm{m} / \mathrm{z} 42$ fragment was also seen in the ESI MS-MS of cyclo(GlyGly) shown in Figure S1.

The labeling experiments showed that Species 5 was able to lose either DKP carbonyl, but not necessarily in a 1:1 ratio. The occurrence of two product ions with $\mathrm{m} / \mathrm{z} 85$ makes it difficult to determine exactly the percentage of each form of Species 9. The current estimate indicates that Species 9 has $\mathrm{m} / \mathrm{z} 85$ (retention of an ${ }^{18} \mathrm{O}$ ) approximately $42 \%$ of the time. The non-randomized mix of product ion $\mathrm{m} / \mathrm{z} 83$ and $\mathrm{m} / \mathrm{z} 85$ indicates that the system may be more complex than shown in Scheme 1. It is likely that although Scheme 1 seems to be the dominant pathway, with the energy available in this CID there could be competing fragmentation channels with different starting conformers proceeding through different pathways.

The keys to the ultimate production of deprotonated 2-imidazoline 4,5-one product ion from GlySer are the cis conformation of the starting dipeptide and the formation of the alpha enolate ion of Ser, which then allow GlySer to form a cyclic DKP intermediate.

\section{Acknowledgements}

The PE/Sciex mass spectrometer used in this work was a gift from the Department of Drug Metabolism and Pharmacokinetics, Merck Research Laboratories. BT was supported by National Science Foundation grant CHE-1213521 awarded to GCS. Computational work was supported by NSF grants CHE-0116435, CHE-0521063, CHE0849677, and CHE-1229354 awarded to GCS as part of the MERCURY highperformance computer consortium. This research used the National Science Foundation XSEDE resources provided by the Texas Advanced Computing Center (TACC) under grant numbers TG-CHE090095 and TG-CHE120025. JSS thanks Prof. Nico M.M. Nibbering for early encouragement and helpful discussions.

\section{Appendix A. Supplementary data}

Supplementary data associated with this article can be found, in the online version, at http://dx.doi.org/10.1016/j.ijms.201x.xx.xxx

\section{References}

[1] K. Biemann, S.A. Martin, Mass spectrometric determination of the amino acid sequence of peptides and proteins, Mass Spectrom. Rev. 6 (1987) 1-76.

[2] B. Paizs, S. Suhai, Fragmentation pathways of protonated peptides, Mass Spectrom. Rev. 24 (2005) 508-548.

[3] D.M.Waldera-Lupa, A. Stefanski, H.E. Meyer, K. Stuhler, The fate of b-ions in the two worlds of collision-induced dissociation, Biochimica et Biophysica Acta 1834 (2013) 2843-2848. 
[4] O.S. Skinner, A.D. Catherman, B.P. Early, P.M. Thomas, P.D. Compton, N.L.

Kelleher, Fragmentation of integral membrane proteins in the gas phase, Anal Chem 86 (2014) 4627-4634.

[5] A.G. Harrison, Sequence-specific fragmentation of deprotonated peptides containing H or alkyl side chains, J. Am. Soc. Mass Spectrom. 12 (2001) 1-13.

[6] J.H. Bowie, C.S. Brinkworth, S. Dua, Collision-induced fragmentations of the (M-H) parent anions of underivatized peptides: an aid to structure determination and some unusual negative ion cleavages, Mass Spectrom. Rev. 21 (2002) 87-107.

[7] D. Bilusich, J.H. Bowie, Fragmentations of (M-H) ${ }^{-}$anions of underivatized peptides. Part 2: Characteristic cleavages of ser and cys and of disulfides and other posttranslational modifications, together with some unusual internal processes, Mass Spectrom. Rev. 28 (2009) 20-34.

[8] D. Pu, N.L. Clipston, C.J. Cassady, A comparison of positive and negative ion collision-induced dissociation for model heptapeptides with one basic residue, Journal of Mass Spectrometry 45 (2010) 297-305.

[9] T.Wang, T.T.N. Tran, A.N. Calabrese, J.H.Bowie, Backbone fragmentations of [M$\mathrm{H}]^{-}$anions from peptides. Reinvestigation of the mechanism of the beta prime cleavage, Rapid Commun. Mass Spectrom. 26 (2012) 1832-1840.

[10] S.S. Bokatzian-Johnson, M.L. Stover, D.A. Dixon, C.J. Cassady, A comparison of the effects os amide and acid groups at the c-terminus on the collision-induced dissociation of deprotonated peptides, J. Am. Soc. Mass Spectrom. 23 (2012) 1544-57.

[11] M. Takayama, S. Sekiya, R. Iimuro, S. Iwamoto, K. Tanaka, Selective and nonselective cleavages in positive and negative CID of the fragments generated from insource decay of intact proteins in MALDI-MS, J. Am. Soc. Mass Spectrom. 25 (2014) 120-131.

[12] P. Roepstorff, J. Fohlman, Proposal for a common nomenclature for sequence ions in mass spectra of peptides, Biomed. Mass Spectrom. 11 (1984) 601.

[13] R.A.J. O'Hair, S. Gronert, C.H. Depuy, J.H. Bowie, Gas phase ion chemistry of the acetic acid enolate anion $\left[\mathrm{CH}_{2} \mathrm{CO}_{2} \mathrm{H}\right]^{-}$, J. Am. Chem. Soc. 111 (1989) 3105-6.

[14] R.J. Waugh, M. Eckersley, J.H. Bowie, Collision induced dissociations of deprotonated peptides: dipeptides containing serine or threonine, Int J. Mass Spectrom. Ion Processes 98 (1990) 135-45.

[15] D. Pu, C.J. Cassady, Negative ion dissociation of peptides containing hydroxyl side chains, Rapid Commun. Mass Spectrom. 22 (2008) 91-100. 
[16] J.S. Grossert, M.C. Cook, R.L. White, The influence of structural features on facile McLafferty-type, even-electron rearrangements in tandem mass spectra of carboxylate anions, Rapid Commun. Mass Spectrom. 20 (2006) 1511-1516.

[17] U.H. Verkerk, J. Zhao, J.K.C. Lau, T.W. Lam, Q. Hao, J.D. Steill, C.T. Siu, J. Oomens, A.C. Hopkinson, K.W. Siu, Structures of the $a_{2}$ ions of Ala-Ala-Ala and PhePhe-Phe,.Int. J. Mass Spectrom. 330-332 (2012) 254-261.

[18] E.A.L. Gillis, J.S. Grossert, R.L. White, Rearrangements leading to fragmentations of hydrocinnamate and analogous nitrogen-containing anions upon collision-induced dissociation, J. Am. Soc. Mass Spectrom. 25 (2014) 388-397

[19] K.F. Medzihradszky, J.C. Trinidad, Unusual fragmentation of pro-ser/thr-containing peptides detected in collision-induced dissociation spectra, J. Am. Soc. Mass Spectrom. 23 (2012) 602-607.

[20] A.G. Harrison, To $b$ or not to $b$ : the ongoing saga of peptide $b$ ions, Mass Spectrom. Rev. 28 (2009) 640-654.

[21] S. Zou, J. Oomens, N.C. Polfer, Competition between diketopiperazine and oxazolone formation in water loss products from protonated ArgGly and GlyArg, Int. J. Mass Spectrom. 316-318 (2012) 12-17.

[22] A.C. Gucinski, J. Chamot-Rooke, V. Steinmetz, A. Somogyi, V.H.Wysocki, Influence of $\mathrm{N}$-terminal residue composition on the structure of proline-containing $\mathrm{b}_{2}$ ions, J Phys. Chem. A 117 (2013) 1291-1298.

[23] G.A. Chass, C.N.J. Marai, D.H. Setiadi, I.G. Csizmadia, A.G. Harrison, A HartreeFock, MP2 and DFT computational study of the structures and energies of " $\mathrm{b}_{2}$ ions derived from deprotonated peptides. A comparison of method and basis set used on relative product stabilities, J. Mol. Struct. (Theochem) 675 (2004) 149-162.

[24] J. Grzetic, J. Oomens, Spectroscopic evidence for an oxazolone structure in anionic b-type peptide fragments, J. Am. Soc. Mass Spectrom. 23 (2012) 290-300.

[25] J. Grzetic J. Oomens, Structure of anionic c-type fragments elucidated by IRMPD spectroscopy, Int. J. Mass Spectrom. 316-318 (2012) 216-226.

[26] J. Grzetic, J. Oomens, Effect of the Asn side chain on the dissociation of deprotonated peptides elucidated by IRMPD spectroscopy, Int. J. Mass Spectrom. 354355 (2013) 70-77.

[27] A.G. Harrison, A.B. Young, Fragmentation of deprotonated N-benzoylpeptides: formation of deprotonated oxazolones, J. Am. Soc. Mass Spectrom. 15 (2004) 446-456. 
[28] A.M. Bradford, R.J. Waugh, J.H. Bowie, D.L. Vollmer, M.L. Gross, Collisioninduced dissociations of deprotonated dipeptide methyl esters containing $\mathrm{H}$, alkyl, or benzyl alpha side-chains, Int. J. Mass Spectrom. Ion Processes 136 (1994) 143-153.

[29] P.Y. Iris Shek, J. K-C. Lau, J. Zhao, J. Grzetic, U.H. Verkerk, J. Oomens, A.C. Hopkinson, K.W.M. Siu, Fragmentations of protonated cyclic-glycylglycine and cyclicalanylalanine, Int. J. Mass Spectrom. 316-318 (2012) 199-205.

[30] P.A. Wabnitz, R.J. Waugh, M.A. Eckersley, S. Dua, T. Blumenthal, J.H. Bowie, The negative ion mass spectra of deprotonated 2,5-diketopiperazines, Int. J. Mass Spectrom. Ion Processes 154 (1996) 193-201.

[31] Y. Guo, S. Cao, D. Wei, X. Zong, X. Yuan, M. Tang, Y. Zhao, Fragmentation of deprotonated cyclic dipeptides by electrospray ionization mass spectrometry, J. Mass Spectrom. 44 (2009) 1188-94.

[32] R. Niles, H.E. Witkowska, S. Allen, S.C. Hall, S.J. Fisher, M. Hardt, Acid-catalyzed oxygen-18 labeling of peptides, Anal. Chem. 81 (2009) 2804-2809.

[33] N. Liu, H. Wu, H. Liu, G. Chen, Z. Cai, Microwave-assisted ${ }^{18}$ O-labeling of proteins catalyzed by formic acid, Anal. Chem. 82 (2010) 9122-9126.

[34] E. Haaf, Peptide and protein quantitation by acid-catalyzed ${ }^{18} \mathrm{O}$-labeling of carboxyl groups, Anal Chem 84 (2012) 304-311.

[35] T.A. Halgren, Merck molecular force field. I. Basis, form, scope, parameterization, and performance of MMFF94, J. Comput. Chem. 17 (1996) 490-519.

[36] Y. Zhao, D.G. Truhlar, The M06 suite of density functionals for main group thermochemistry, thermochemical kinetics, noncovalent interactions, excited states, and transition elements: two new functionals and systematic testing of four M06-class functionals and 12 other functionals, Theor. Chem. Account 120 (2008) 215-241.

[37] M.J. Frisch, G.W. Trucks, H.B. Schlegel, G.E. Scuseria, M.A. Robb, J.R. Cheeseman, G. Scalmani, V. Barone, B. Mennucci, G.A. Petersson, H. Nakatsuji, M. Caricato, X. Li, H.P. Hratchian, A.F. Izmaylov, J. Bloino, G. Zheng, J.L. Sonnenberg, M. Hada, M. Ehara, K. Toyota, R. Fukuda, J. Hasegawa, M. Ishida, T. Nakajima, Y. Honda, O. Kitao, H. Nakai, T. Vreven, J.A. Montgomery, Jr., J.E. Peralta, F. Ogliaro, M. Bearpark, J.J. Heyd, E. Brothers, K.N. Kudin, V.N. Staroverov, R. Kobayashi, J. Normand, K. Raghavachari, A. Rendell, J.C. Burant, S.S. Iyengar, J. Tomasi, M. Cossi, N. Rega, J.M. Millam, M. Klene, J.E. Knox, J.B. Cross, V. Bakken, C. Adamo, J. Jaramillo, R. Gomperts, R.E. Stratmann, O. Yazyev, A.J. Austin, R. Cammi, C. Pomelli, J.W. Ochterski, R.L. Martin, K. Morokuma, V G. Zakrzewski, G.A. Voth, P. Salvador, J.J. Dannenberg, S. Dapprich, A.D. Daniels, Ö. Farkas, J.B. Foresman, J.V. Ortiz, J. Cioslowski, and D.J. Fox, Gaussian 09, Revision D.01, Gaussian, Inc., Wallingford, CT, 2009. 
[38] B. Kanawati, S. Joniec, R. Winterhalter, G.K. Moortgat, Mass spectrometric characterization of small oxocarboxylic acids and gas phase fragmentation mechanisms studied by electrospray triple quadrupole-MS/MS-TOF system and DFT theory, Int. J. Mass Spectrom. 266 (2007) 97-113.

[39] B. Kanawati, S. Joniec, R. Winterhalter, G.K. Moortgat, Mass spectrometric characterization of oxopentanoic acid and gas-phase ion fragmentation mechanisms studied using a triple quadrupole and time-of-fight analyzer hubrid system and density functional theory, Rapid Commun. Mass Spectrom. 22 (2008) 2269-2279. 


\section{Figure, Table, and Scheme captions}

Fig. 1. Product ions of GlySer determined with a Perkin-Elmer/Sciex API III+

Fig. 2. Species 3 to Species 4 conversion. Relative energies are given in Fig. 3.

Fig. 3. Energy profile for GlySer fragmentation. Species and transition states are identified on the $\mathrm{x}$-axis.

Fig. 4. Species 4 to 5 Transition State.

Fig. 5. GlySer ${ }^{18} \mathrm{O}$ exchange. Fragment $\mathrm{m} / \mathrm{z} 165$ contains two ${ }^{18} \mathrm{O}$ atoms.

Table 1. Sequential fragment percent total ion current (\% TIC) from serine-containing dipeptides at given collision energies. Species 1, 3, 5, and 9 are represented in Scheme 1 for GlySer.

Scheme 1. Possible GlySer fragmentation mechanism. Asterisk(*) marks ${ }^{18} \mathrm{O}$. Due to symmetric transitions, Species 9 could result with $\mathrm{m} / \mathrm{z} 83$ or 85 . 